\title{
Selective Recognition: How to Recognize Donors to Increase Charitable Giving
}

\author{
Anya Samek ${ }^{\text {a }}$ \\ Roman M. Sheremeta ${ }^{\text {b,c,* }}$ \\ ${ }^{a}$ Center for Economic and Social Research, University of Southern California \\ 635 Downey Way, Los Angeles, CA 90089, USA \\ ${ }^{\mathrm{b}}$ Weatherhead School of Management, Case Western Reserve University \\ 11119 Bellflower Road, Cleveland, OH 44106, USA \\ ${ }^{\mathrm{c}}$ Economic Science Institute, Chapman University \\ One University Drive, Orange, CA 92866, USA
}

November 24, 2015

\begin{abstract}
Recognizing donors by revealing their identities is important for increasing charitable giving. We conducted a field experiment to examine how different recognition methods impact giving, and found that all forms of recognition that we examined had a positive impact on increasing donations, whereby recognizing only highest donors (positive recognition) and recognizing only lowest donors (negative recognition) had the most pronounced effect. We argue that selective recognition (both positive and negative) creates tournament-like incentives. Recognizing the highest donors activates the desire to seek a positive prize of prestige, thus increasing the proportion of donors who contribute large amounts. Recognizing the lowest donors activates the desire to avoid a negative prize of shame, thus decreasing the proportion of donors who do not contribute or contribute very little. Therefore, selective recognition is an effective tool that can be used in the field by charities to increase donations.
\end{abstract}

JEL Classifications: C93, D64

Keywords: charity donations, recognition, information, experiments

* Corresponding author: Roman M. Sheremeta, rms246@case.edu

We want to thank Tristin Ganter, Phuong Ta and Amanda Chuan for valuable research assistance. Also, we want to thank Sera Linardi, John List, Lise Vesterlund, and participants at the Science of Philanthropy Initiative Conference for helpful discussions and comments. Finally, we wish to thank the John Templeton Foundation through the Science of Philanthropy Initiative for research funding. Any remaining errors are ours. 


\section{Introduction}

"Positive recognition has long been a trusted way of raising money on college campuses, where buildings, benches, and even the insides of library books bear the names of donors. But in an effort to spur gifts among young soon-to-be alumni, students at two Ivy League institutions are trying a different approach: publicizing the names of seniors who don't contribute to their class." - Chronicle of Higher Education ${ }^{1}$

The desire for social approval is one of the reasons why individuals act more generously when their generosity is viewable by others (Hollander, 1990). Studies have shown that recognizing donors by revealing their identity increases contributions to public goods and donations to charities. ${ }^{2}$ However, very little is known about what kind of recognition is more effective in the field. For example, a charity may decide to recognize all donors by printing their names in newsletters. Alternatively, the charity may choose to recognize only the highest donors by naming buildings after them or posting their names on the walls. In our opening example, two Ivy League universities chose yet another approach by publicizing the names of seniors who do not contribute to their class, thus attempting to shame the non-contributors into giving. Although one can provide a number of arguments for or against using each of these approaches in practice, it is an empirical question of which approach is better at increasing charitable donations.

We conducted a randomized field experiment in a suburb of Chicago to investigate the impact of different recognition schemes on donations to a charity. Over 200 individuals recruited from the community were randomly assigned to small groups of 5-8 individuals and had an

\footnotetext{
${ }^{1}$ From the Chronicle of Higher Education: http://chronicle.com/article/Students-at-2-Ivy-League/125056/.

${ }^{2}$ Studies showing the positive effect of recognition include Andreoni and Petrie (2004), Rege and Telle (2004), Soetevent (2005), Karlan and McConnell (2014), Jones and Linardi (2014), and Samek and Sheremeta (2014). Social recognition has also been found effective in voter turnout, blood donation, consumption of private goods, and tournaments (Gerber et al., 2008; Lacetera and Macis, 2010; Mago et al., 2015; Clingingsmith and Sheremeta, 2015).
} 
opportunity to donate part of their $\$ 10$ earnings from the experiment to the American Red Cross. In the no recognition treatment, only donation amounts were displayed to the group at the end of the experiment. In the full recognition treatment, we also publicized all individuals' names next to their donations. In the positive recognition treatment, we publicized only the names of the highest donors next to their donations. In the negative recognition treatment, we publicized the names of the lowest donors (including publicizing those who gave $\$ 0$ ).

We found that all forms of recognition have a positive impact on increasing donations, with selective recognition (both positive and negative) having the most pronounced and significant effect. However, the underlying mechanisms for why positive and negative recognition are effective are very different. Negative recognition encourages higher donations through discouraging donations lower than $\$ 5$, while positive recognition encourages maximum donations of $\$ 10$. This suggests that recognition encourages giving in two important ways: (i) participants in the negative recognition treatment donate more to avoid shame from being recognized as a low donor while (ii) participants in the positive recognition treatment donate more to experience prestige from being recognized as a high donor. Participants who were most affected by recognition are those who said that it is very important what others think about them. Finally, we found that participants who regularly donate to charities donated more in our experiment while participants who regularly donate to church donate less in our experiment, suggesting that donations to charities and donations to church are substitutes.

Our findings have practical implications. For example, we show that recognizing the highest or the lowest donors by revealing their identities is the most effective recognition method. The main reason is that selective recognition creates tournament-like incentives, encouraging donors to seek a positive prize of prestige and avoid a negative prize of shame. 
Therefore, when recognizing donors or when publishing annual reports, practitioners should be creative in utilizing tournament-like incentives by recognizing their top contributors, and in some instances (as in the case with our opening example) shaming non-contributors. However, practitioners should be careful when choosing negative incentives (such as shaming noncontributors), because they also face the first-order problem of attracting and retaining contributors. Given the opportunity of free entry and exit, individuals may simply avoid contributing to communal and charity groups that identify the lowest contributors.

\section{Methodology}

\subsection{Theoretical Background}

Related work has proposed different motivations for giving to charities. Behavioral arguments for why individuals contribute positive amounts to charities and public goods include pure altruism (Bergstrom et al., 1986; Harbaugh et al., 2007), 'warm glow' (Andreoni, 1989, 1990; Gneezy et al., 2014) and inequality aversion (Rabin, 1993; Fehr and Schmidt, 1999). It is also possible that individuals incur a utility loss by contributing below the socially acceptable amount, whereby the acceptable amount can be signaled by the fundraiser through recommended amounts (Edwards and List, 2013) or through giving information about a past amount given by a previous donor (Croson and Shang, 2008; Shang and Croson, 2009).

Empirical evidence that individuals give more when they are recognized suggests a role for recognition as an additional reason for giving (Andreoni and Petrie, 2004; Soetevent, 2005; Karlan and McConnell, 2014; Samek and Sheremeta, 2014). According to the model of Benabou and Tirole (2006), individuals have a utility for social image. When recognition is introduced, an effort to preserve a high social image adds to the motivation to give to charity. In a different model, Vesterlund (2003) suggests that recognition increases contributions since donors have a 
preference for being role models for others. Therefore, we should expect that the desire for preserving social image (as suggested by Benabou and Tirole, 2006) and the quest to be a role model for others (as suggested by Vesterlund, 2003) should encourage higher donations when all donors are recognized (full recognition treatment) compared to the case when no donors are recognized (no recognition treatment).

According to Samek and Sheremeta (2014), recognizing the highest donors activates the desire to seek prestige (Hollander, 1990; Harbaugh, 1998), while recognizing the lowest donors activates the desire to avoid shame (Frank, 1988; Gilbert, 1998; Ketelaar, 2004). Therefore, relative to the baseline treatment (no recognition treatment) we expect higher donations both when the highest donors are recognized (positive recognition treatment) and when the lowest donors are recognized (negative recognition treatment).

The comparison of positive and negative recognition versus full recognition requires additional consideration. On one hand, full recognition incorporates both positive and negative recognition, since recognizing all donors implies also recognizing the highest and the lowest donors. On the other hand, recognizing only the highest or only the lowest donors singles them out and makes their social identities more salient. This singling out amplifies prestige or shame since all attention is focused only on the sub-set of donors who are recognized. In a sense, singling out creates tournament-like incentives, encouraging donors to seek a positive prize of prestige and avoid a negative prize of shame. ${ }^{3}$ Such incentives should strengthen the effects of prestige under positive recognition and shame under negative recognition, thus generating higher donations than full recognition. In addition, individuals who care most about what others think of them might be more likely to be affected by the negative and positive recognition relative to

\footnotetext{
${ }^{3}$ It is well documented that tournament-like incentives are powerful at motivating individuals (Dechenaux et al., 2015). Moreover, such incentives are even more powerful than predicted by the standard game theory (Sheremeta, 2013, 2015, 2016).
} 
individuals who do not care as much about what others think, and individuals who perceive themselves as high or low on the social ladder may be differently affected by the treatments. Ultimately, this is an empirical question that we address with our experiment.

\subsection{Experimental Design}

In the Harrison and List (2004) taxonomy, our experiment is a 'framed field experiment'. The experiment involved 205 individuals who were recruited from families participating in an early childhood study in a suburb of Chicago. ${ }^{4}$ Upon arriving to the experiment, participants were randomly assigned to small groups of 5-8 individuals and had the opportunity to donate part of their endowment to the American Red Cross. Each group participated in a separate session and room. At the beginning of the session, all participants identified themselves by writing their first and last name on a nametag that was displayed to the others at all times. Participants sat in a circle facing each other and were given a walled lapboard (that we call a 'privacy screen') so that all decisions could be made in private. Participants were instructed not to communicate with one another. Participants were given the instructions, which included a description of the American Red Cross (see the Appendix). The researcher also handed out a short quiz on understanding and went over the responses with the participants.

Each participant earned $\$ 10$ for coming to the experiment, which was announced in advance and distributed at the end of the experiment. Participants received an additional endowment of $\$ 10$ (ten, $\$ 1$ bills) to use in the experiment. Participants placed the amount that

\footnotetext{
${ }^{4}$ Recruitment for the study was done through the 'Living Lab' at the Chicago Heights Early Childhood Center in Chicago Heights, IL. Over 2,000 subjects make up this pool of households from Chicago Heights and the surrounding area, and are invited to participate in field experiments on a semi-regular basis. Participants in this study had not participated in a similar study in the past, and we asked participants to indicate whether they knew anyone else in their group, separating them into separate groups if they said they knew anyone. In a survey following the experiment, we also asked participants state whether anyone in their group was a friend, and about $7 \%$ of participants said they were friends with someone in their group. Our results do not change when we control for this in the analysis.
} 
they wanted to give to the Red Cross in one envelope (labeled 'give') and the amount that they wanted to keep in the other envelope (labeled 'keep'). This decision was made quietly and in private. The researcher collected the 'give' envelopes and tallied the totals at the back of the room. The donation decision was only made once.

At the end of the decision, all individual donations (including $\$ 0$ donations) were displayed on the board at the front of the room sorted from the largest to the smallest. We conducted four treatments in which we experimentally manipulated the recognition information available to participants at the end of the experiment (see Table 1). In the no recognition treatment, no additional information was available about the amounts that each person gave. In the full recognition treatment, we told participants prior to their decision that the first and the last name of each group member would be written next to each donation amount at the end. In the positive recognition treatment, participants learned that the first and the last name of two highest donors would be displayed, but that the remaining participants would not be recognized. Finally, in the negative recognition treatment, participants learned that the first and the last name of two lowest donors (including \$0) would be displayed, and the other participants would not be recognized. In case of ties, the order of names was randomly determined.

At the end of the experiment, participants responded to a short questionnaire, which included basic demographic questions as well as questions about overall charitable giving habits, tendency to care about what others think and one's perceived social status. The experiment lasted approximately 30 minutes. The researchers sent all the donated money to the Red Cross via web payment within a week following the experiment, and participants were instructed that they could receive a confirmation email if they wished. 


\section{Results}

\subsection{Average Donations}

Figure 1 summarizes the average donation by treatment. In the positive recognition treatment the average donation is $\$ 6.93$, followed by $\$ 6.29$ in the negative recognition treatment, then by $\$ 6.02$ in the full recognition treatment, and finally by $\$ 5.26$ in the no recognition treatment. Even in the baseline no recognition treatment, individuals on average give more than $50 \%$ of their available earnings to the Red Cross. Compared to the real donation experiment with university students of Eckel and Grossman (1996), individuals in our experiment gave more. A major difference in our experiment is that even in the baseline treatment, all donation amounts are immediately revealed, while in Eckel and Grossman's experiment, no donation amounts are revealed and the experiment was double blind. In addition, literature suggests that community members (as in our experiment) tend to give more than students to charity (Carpenter et al., 2008).

When comparing the four treatments, we find that all forms of recognition increase donations relative to the baseline treatment, with positive recognition and negative recognition having the highest impact. Compared to no recognition, individuals on average donate $\$ 1.67$ more when positive recognition is introduced (Wilcoxon Mann-Whitney test, $\mathrm{p}$-value $=0.01$ ) and donate $\$ 1.03$ more when negative recognition is introduced (Wilcoxon Mann-Whitney test, pvalue $=0.05)$. Individuals also donate $\$ 0.76$ more in full recognition relative to no recognition; however, this is not significant at the conventional level (Wilcoxon Mann-Whitney test, p-value $=0.12$ ). We do not find any significant differences between the positive, negative and full recognition treatments (all p-values $>0.20$ ). 


\subsection{Distribution of Donations}

The underlying mechanisms for why positive recognition and negative recognition are so effective are very different. Figure 2 displays the distribution of donations across treatments. There are several interesting patterns that emerge. First, we see anchor points at a gift of $\$ 5$ (50\% of the endowment, and $25 \%$ of total earnings) and $\$ 10$ (100\% of the endowment, and $50 \%$ of total earnings). Second, these anchor points become stronger when recognition is introduced. Under no recognition, $40 \%$ of participants donate less than $\$ 5,28 \%$ donate exactly $\$ 5$, and $25 \%$ donate exactly $\$ 10$. Full recognition significantly reduces donations less than $\$ 5$ (from $40 \%$ to $20 \%$, Fisher's exact test, $\mathrm{p}$-value $=0.02$ ) and increases (although not significantly) donations of $\$ 5$ (from $28 \%$ to $41 \%$, Fisher's exact test, p-value $=0.16$ ). Similarly, negative recognition significantly reduces donations less than $\$ 5$ (from $40 \%$ to $19 \%$, Fisher's exact test, p-value $=$ 0.02 ) and increases (although not significantly) donations of $\$ 5$ (from $28 \%$ to $38 \%$, Fisher's exact test, $\mathrm{p}$-value $=0.30$ ). On the other hand, positive recognition does not significantly reduce donations less than $\$ 5$ (from $40 \%$ to $24 \%$, Fisher's exact test, $\mathrm{p}$-value $=0.14$ ), but it significantly increases maximum donations of $\$ 10$ (from $25 \%$ to $49 \%$, Fisher's exact test, p-value $=0.01$ ).

In summary, while all recognition treatments result in higher donations than no recognition, as Figure 1 and Figure 2 demonstrate, the underlying reasons for the increase are different. Negative recognition increases donations through discouraging donations lower than $\$ 5$, suggesting that participants increase their donations to avoid shame. Positive recognition increases donations by encouraging maximum donations of $\$ 10$, suggesting that participants are motivated by prestige. 


\subsection{Determinants of Giving}

In this section, we examine the determinants of giving by comparing the outcomes to the responses to a questionnaire that was completed at the end of the experiment. The questionnaire included questions about participants' gender, how often they give to their church or charities (Likert scale from 1 = "strongly disagree" to $5=$ "strongly agree"), whether it is important how others think about them (Likert scale from $1=$ "strongly disagree" to $5=$ "strongly agree"), and how they rank themselves on the social ladder (Likert scale from $1=$ "at the very bottom" to 10 = "at the very top"). Table 2 shows the summary of participants' responses to these questions. About $72 \%$ of our participants are females. On average participants place themselves in the middle of the social ladder. ${ }^{5}$ Most commonly participants "agree" with the statement that they regularly give to their church and to other charities. When asked whether it is important what others think of them, participants commonly answer "neither agree, nor disagree."

Next, we explore how characteristics described in Table 2 impact individual donations. Table 3 reports estimation results of different ordinary least squares regressions with robust standard errors. In all regressions the dependent variable is the amount of donation. Given our small sample and the fact that all recognition works in the same direction, we combine all recognition treatments. The independent variables in regression (1) are the recognition treatment dummy and a constant. Consistent with the non-parametric tests, we find that recognition significantly increase donations. On average, participants give $\$ 1.13$ more when they know that they will be publicly recognized for their donations. In regression (2) we include additional

\footnotetext{
${ }^{5}$ Participants were shown a picture with a ladder and were asked the following question: "Think of this ladder as representing where people stand. At the top of the ladder are the people who are best off - those who have the most money, the most education, and the most respected jobs. At the bottom of the ladder are the people who are the worst off - who have the least money, least education, and the least respected jobs or no job. The higher up you are on the ladder, the closer you are to the people at the very top; the lower you are, the closer you are to the people at the very bottom. Where would you place yourself on this ladder?"
} 
controls, and find that recognition is still significant and the magnitude is large. Additionally, we find that participants who strongly agree with the statement "I regularly give to charities (excluding church)" donate $\$ 1.23$ more to the Red Cross in our experiment (significant give_charities variable), while participants who strongly agree with the statement "I regularly give to my church" donate $\$ 0.98$ less in our experiment (marginally significant give_church variable). This suggests that donations to charities and donations to church are substitutes. In regression (3) we add the interactions of recognition with other explanatory variables. Interestingly, recognition becomes insignificant and the magnitude drops to $\$ 0.05$. Examining the results, we see that the effect of recognition comes entirely from people who say that it is very important what "others think about them." The interaction recognition $\times$ others_think is highly significant and the magnitude is large. An intuitive interpretation is that participants who care about what others think about them are most affected by recognition.

\section{Discussion and Conclusion}

We conducted a framed field experiment in a suburb of Chicago to investigate how recognition impacts charity donations. We varied recognition in four separate treatments and found that all forms of recognition have a positive impact on increasing donations, with positive recognition and negative recognition having the highest (and statistically significant) impact.

We suggest several reasons for why positive and negative recognitions are so effective at increasing charitable donations. Selective recognition (both positive and negative) creates tournament-like incentives. Recognizing the highest donors activates the desire to seek prestige (a positive prize) from being a high donor (Hollander, 1990; Harbaugh, 1998), thus increasing the proportion of donors who contribute the full amount of their income. Recognizing the lowest 
donors activates the desire to avoid shame (a negative prize) from being a low donor (Frank, 1988; Gilbert, 1998; Ketelaar, 2004), thus decreasing the proportion of donors who do not contribute (or contribute very little) and increasing the proportion of donors who contribute half of their income. Compared to the full recognition treatment, recognizing only the highest or only the lowest donors singles these donors out and makes their social identities more salient, amplifying prestige or shame (since all attention is focused only on the two donors). Therefore, while all forms of recognition positively impact charitable donations, positive and negative recognition has the most significant effect.

The fact that positive recognition is so effective is surprising, given the recent findings of Samek and Sheremeta (2014), who find that in a laboratory experiment negative recognition increases contributions to the public good while positive recognition does not. There are a number of important differences between our two studies which may explain different findings. First, unlike the public goods game, individual donations do not directly impact the payoffs of the group members who view the recognition information. In the public goods game, participants who are identified as top contributors may be viewed as "suckers", preventing them from contributing to the public goods, while it is not the case with charitable donations to the Red Cross. Moreover, individuals receive no monetary benefit from the amount of total gifts given to the Red Cross, abstracting away from concerns about fairness, inequality-aversion and freeriding, which are important social motivators in public goods games (Ledyard et al, 1995). Finally, our framed field experiment used participants from a suburb of Chicago in the setting that closely resemble a natural setting in which people donate to charities.

The fact that positive recognition matters has been a commonly-held belief (Vesterlund, 2003; Benabou and Tirole, 2006) and it has been supported by previous research (Andreoni and 
Petrie, 2004; Rege and Telle, 2004; Soetevent, 2005; Anderson et al., 2009; Samek and Sheremeta, 2014). However, our results also point out the effectiveness of negative recognition. In our opening example, we quoted a story described in the Chronicle of Higher Education in which two Ivy League universities chose to increase donation amounts from their soon-to-be alumni by "publicizing the names of seniors who don't contribute to their class." This may seem like a controversial strategy (and indeed it generated many debates after the article was published); however, the bottom line is that negative recognition works. Because shame appears to be a powerful motivator to encourage giving, one may ask the question: why do not all social groups, charity organizations and online communities practice displaying the lowest contributors? While these institutions face the problem of increasing contributions, they also face the first-order problem of attracting and retaining contributors. Given the opportunity of free entry and exit, individuals may simply avoid contributing to communal and charity groups that identify the lowest contributors. Therefore, in the long run a negative recognition policy may backfire. We see the long term effects of recognition as a fruitful avenue for the future research. 


\section{References}

Andreoni, J. (1989). Giving with impure altruism: Applications to charity and Ricardian equivalence. Journal of Political Economy, 97, 1447-1458.

Andreoni, J. (1990). Impure altruism and donations to public goods: A theory of warm-glow giving. Economic Journal, 100, 464-477.

Andreoni, J., \& Petrie, R. (2004). Public goods experiments without confidentiality: A glimpse into fund-raising. Journal of Public Economics, 88, 1605-1623.

Benabou, R., \& Tirole, J. (2006). Incentives and prosocial behavior. American Economic Review, 99, 544-555.

Bergstrom, T., Blume, L., \& Varian, H. (1986). On the private provision of public goods. Journal of Public Economics, 29, 25-49.

Carpenter, J., Connolly, C., \& Myers, C.K. (2008). Altruistic behavior in a representative dictator experiment. Experimental Economics, 11, 282-298.

Clingingsmith, D., \& Sheremeta, R.M. (2015). Status and the demand for visible goods: Experimental evidence on conspicuous consumption. Working Paper.

Croson, R., \& Shang, J. Y. (2008). The impact of downward social information on contribution decisions. Experimental Economics, 11, 221-233.

Dechenaux, E., Kovenock, D., \& Sheremeta, R.M. (2015). A survey of experimental research on contests, all-pay auctions and tournaments. Experimental Economics, 18, 609-669.

Eckel, C.C., \& Grossman, P.J. (1996). Altruism in anonymous dictator games. Games and Economic Behavior, 16, 181-191.

Edwards, J.T., \& List, J.A. (2014). Toward an understanding of why suggestions work in charitable fundraising: Theory and evidence from a natural field experiment. Journal of Public Economics, 114, 1-13.

Fehr, E., \& Schmidt, K.M. (1999). A theory of fairness, competition, and cooperation. Quarterly Journal of Economics, 114, 817-868.

Frank, R H. (1988). Passions within reason: The strategic role of the emotions: WW Norton \& Co.

Gerber, A.S., Green, D.P., \& Larimer, C.W. (2008). Social pressure and voter turnout: Evidence from a large-scale field experiment. American Political Science Review, 102, 33-48.

Gilbert, P. (1998). What is shame? Some core issues and controversies. In P. Gilbert \& B. Andrews (Eds), Shame: Interpersonal behaviour, psychopathology and culture (pp. 3-38). New York: Oxford University Press.

Gneezy, U., Keenan, E.A., \& Gneezy, A. (2014). Avoiding overhead aversion in charity. Science, 346(6209), 632-635.

Harbaugh, W.T. (1998). The prestige motive for making charitable transfers. American Economic Review, 88, 277-282.

Harbaugh, W.T., Mayr, U., \& Burghart, D.R. (2007). Neural responses to taxation and voluntary giving reveal motives for charitable donations. Science, 316(5831), 1622-1625.

Harrison, G. W., \& List, J. A. (2004). Field experiments. Journal of Economic Literature, 42, 1009-1055.

Hollander, H. (1990). A social exchange approach to voluntary cooperation. American Economic Review, 80, 1157-1167.

Jones, D., \& Linardi, S. (2014). Wallflowers: Experimental evidence of an aversion to standing out. Management Science, 60, 1757-1771. 
Karlan, D., \& McConnell, M.A. (2014). Hey look at me: The effect of giving circles on giving. Journal of Economic Behavior and Organization, 106, 402-412.

Ketelaar, T. (2004). Ancestral emotions, current decisions: Using evolutionary game theory to explore the role of emotions in decision-making. In C. Crawford \& C. Salmon (Eds.), Darwinism, public policy and private decisions (pp. 145-168). Mahwah, NJ: Erlbaum.

Lacetera, N. \& Macis, M. (2010). Social image concerns and prosocial behavior: Field evidence from a nonlinear incentive scheme. Journal of Economic Behavior and Organization, 76, 225-237.

Ledyard, J. (1995). Public goods: A survey of experimental research. In J. Kagel and A.E. Roth (Eds.) Handbook of Experimental Economics, Princeton, NJ.

Mago, S., Samek, A., \& Sheremeta, R.M. (2015). Facing your opponents: Social identification and information feedback in contests. Journal of Conflict Resolution, forthcoming.

Rabin, M. (1993). Incorporating fairness into game theory and economics. American Economic Review, 83, 1281-1302.

Rege, M., \& Telle, K. (2004). The impact of social approval and framing on cooperation in public good situations. Journal of Public Economics, 88, 1625-1644.

Samek, A.S., \& Sheremeta, R.M. (2014). Recognizing contributors: An experiment on public goods. Experimental Economics, 17, 673-690.

Shang, J., \& Croson, R. (2009). A field experiment in charitable contribution: The impact of social information on the voluntary provision of public goods. Economic Journal, 119, 1422-1439.

Sheremeta, R.M. (2013). Overbidding and heterogeneous behavior in contest experiments. Journal of Economic Surveys, 27, 491-514.

Sheremeta, R.M. (2015). Behavioral dimensions of contests. In Congleton, R.D., Hillman, A.L., (Eds.), Companion to political economy of rent seeking, London: Edward Elgar.

Sheremeta, R.M. (2016). Impulsive behavior in competition: Testing theories of overbidding in rent-seeking contests. Working Paper.

Soetevent, A. (2005). Anonymity in giving in a natural context- a field experiment in 30 churches. Journal of Public Economics, 89, 2301-2323.

Vesterlund, L. (2003). The informational value of sequential fundraising. Journal of Public Economics, 87, 627-657. 
Table 1: Summary of Treatments

\begin{tabular}{lcccc}
\hline \hline Treatment & $\begin{array}{c}\text { Display of Donation } \\
\text { Amounts }\end{array}$ & $\begin{array}{c}\text { Linking Identities } \\
\text { to Donations }\end{array}$ & $\begin{array}{c}\text { Number of } \\
\text { Individuals }\end{array}$ & $\begin{array}{c}\text { Number of } \\
\text { Groups }\end{array}$ \\
\hline No Recognition & Yes & None & 57 & 9 \\
Full Recognition & Yes & All & 51 & 8 \\
Negative Recognition & Yes & Lowest Two & 52 & 8 \\
Positive Recognition & Yes & Highest Two & 45 & 7 \\
\hline
\end{tabular}

Table 2: Responses of Participants

\begin{tabular}{l|c|cccc}
\hline \hline Question & Measure & Mean & Min & Median & Max \\
\hline Are you male or female? & Indicator & 0.72 & 0 & 2 & 1 \\
Where would you place yourself on a ladder? & Likert scale & 5.27 & 1 & 5 & 10 \\
What others think of me is very important to me & Likert scale & 3.10 & 1 & 3 & 5 \\
I regularly give to my church & Likert scale & 4.05 & 1 & 4 & 5 \\
I regularly give to charities (excluding church) & Likert scale & 3.74 & 1 & 4 & 5 \\
\hline
\end{tabular}

Table 3: Regression of Individual Donations on Determinants of Giving

\begin{tabular}{|c|c|c|c|}
\hline Dependent variable, donation & (1) & $(2)$ & (3) \\
\hline recognition & $1.13 * *$ & $1.17 * *$ & 0.05 \\
\hline [ 1 if recognition treatment $]$ & $(0.50)$ & $(0.55)$ & $(2.07)$ \\
\hline others_think & & 0.71 & $-1.89 * *$ \\
\hline [1 if strongly agree] & & $(0.70)$ & $(0.92)$ \\
\hline female & & -0.05 & -1.59 \\
\hline [1 if female] & & $(0.60)$ & (1.04) \\
\hline ladder & & -0.13 & -0.22 \\
\hline [how high on the ladder] & & $(0.13)$ & $(0.25)$ \\
\hline give_church & & $-0.98 *$ & -0.91 \\
\hline [1 if strongly agree] & & $(0.70)$ & $(0.92)$ \\
\hline give_charities & & $1.23 * *$ & 1.55 \\
\hline [1 if strongly agree] & & $(0.60)$ & $(1.26)$ \\
\hline recognition $\times$ others_think & & & $3.49 * * *$ \\
\hline [interaction term] & & & $(1.19)$ \\
\hline recognition $\times$ female & & & $2.25^{*}$ \\
\hline [interaction term] & & & (1.27) \\
\hline recognition $\times$ ladder & & & 0.14 \\
\hline [interaction term] & & & $(0.29)$ \\
\hline recognition $\times$ give_church & & & -0.04 \\
\hline [interaction term] & & & $(1.26)$ \\
\hline $\begin{array}{l}\text { recognition } \times \text { give_charities } \\
\text { [interaction term] }\end{array}$ & & & $\begin{array}{l}-0.30 \\
(1.46)\end{array}$ \\
\hline constant & $5.26 * * *$ & $4.72 * * *$ & $5.46 * * *$ \\
\hline [constant term] & $(0.43)$ & $(1.03)$ & $(1.76)$ \\
\hline Observations & 205 & 164 & 164 \\
\hline
\end{tabular}


Figure 1: Average Donations by Treatment

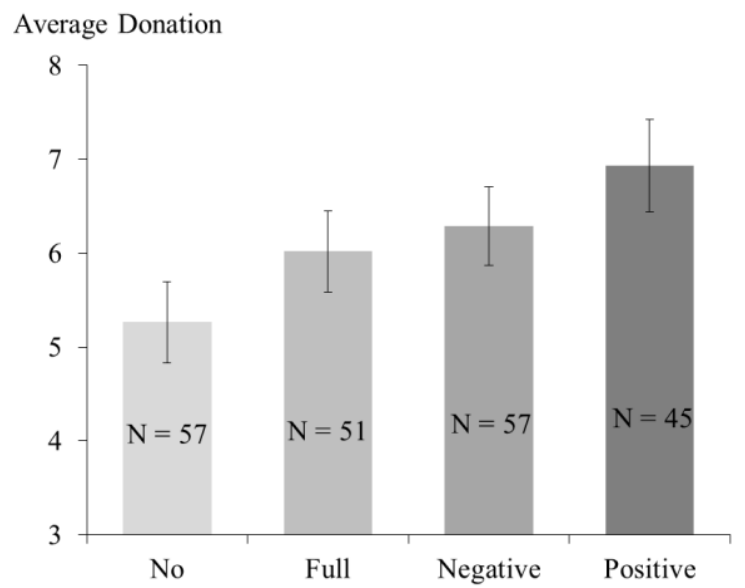

Note: The error bars represent the standard error of the mean.

Figure 2: Distribution of Donations by Treatment
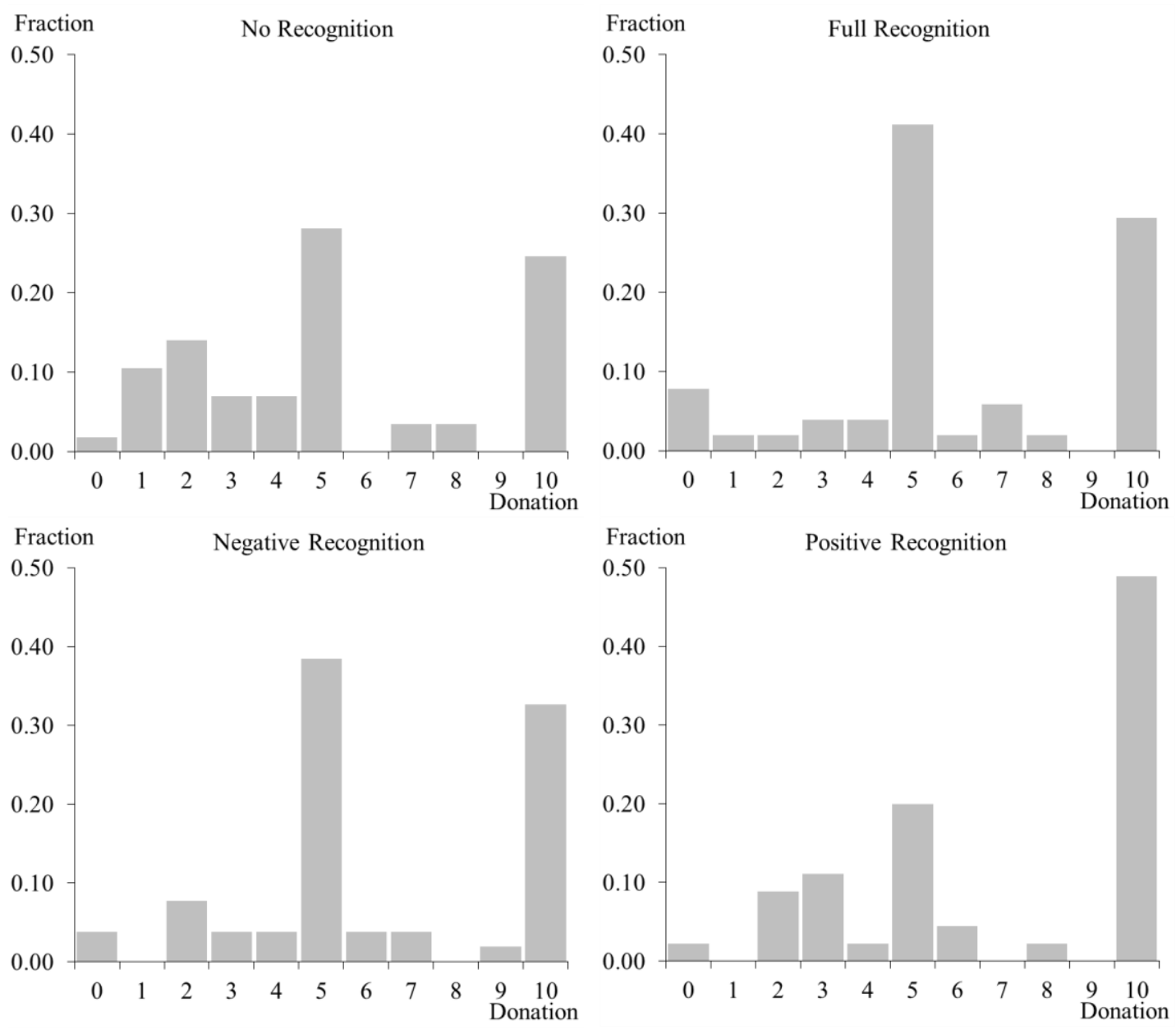


\section{Appendix: Instructions}

\section{Welcome!}

Welcome to the activity. To thank you for coming, I'm going to hand out your $\$ 10$ show up payment to you now.

In this activity we want to see the choices that people make. You will be making choices on your own and in private. So it is very important that you remain silent and do not try to look at other people's choices. If you have any questions, please raise your hand and I will come answer your questions in private.

First, to prepare for the activity, please write your FIRST and LAST name on both sides of your nametag and clip it on the front of your privacy box like this. I will come around and record the names of everyone in the group on my record sheet.

\section{ACTIVITY INSTRUCTIONS}

What will we be doing?

In the activity, you are going to get an additional \$10. You are going to decide how much to keep for yourself, and how much to give to the American Red Cross. You may keep all, some or none of the money for yourself or give none, some or all of the money to the Red Cross. It is completely up to you. You will only make this decision once.

Here is some information about the American Red Cross
The Red Cross is a charity organization led by volunteers, and
provides relief to victims of disaster and helps people prevent,
prepare for, and respond to emergencies. For example, in the past
few months, the Red Cross helped by offering shelter to people
when their homes were destroyed due to high winds and flooding this month. Donations help the Red Cross
provide food, water and medical supplies to different parts of the world in times of need.

You will get two envelopes, $\$ 10$ in $\$ 1$ bills and a record sheet.

You will put the dollars that you want to keep in the blue envelope that says, "keep." You will put dollars that you want to give to the Red Cross in the red envelope that says, "give."

Please also write down the amount you chose to give on your record sheet.

What you keep or give is completely up to you, we just want to know what choice you would make. Take your time in making your decision, we won't go on until everyone is finished.

\section{What happens when everyone is finished?}

Do not seal your envelopes yet. I will come around and I will count up the number of dollars in your red "give" envelope, check to make sure it is correctly written on your record sheet, and write that down next to your name on my record sheet. So please keep your "give" envelope out. Next, I will ask you to seal your "give" envelope and drop it in this Red Cross box.

After I recorded everyone's gift, I'm going to write down on the flip chart at the front of the room the amounts that each person gave, starting with the highest gift and ending with the lowest gift. All gift amounts will be listed, including $\$ 0$ gifts. I'll also add up the total gift of the group and write it on the bottom.

\section{[TREATMENT SPECIFIC INSTRUCTIONS]}

$\underline{\text { None }}$ 
Then, I'll announce the amounts out loud. I will not list anyone's name next to their donation, so your donation is completely anonymous to the rest of the group.

\section{Full}

Then, I will write down each person's name next to their donation, so everyone in your group knows what you gave. I'll also announce the amounts and names out loud. Note that if any two amounts are exactly the same, one of the names will be randomly chosen to be listed first.

\section{$\underline{\text { Negative }}$}

Then, for the two people who gave the lowest amount, I will write down each person's name next to their donation, so everyone in your group knows what these two people gave. However, the donation made by the rest of the group who are not the two lowest givers will be completely anonymous. I'll also announce the amounts out loud, and I will announce the names of the two lowest givers out loud. Note that if two amounts are exactly the same, one of the names will be randomly chosen to be listed first.

\section{$\underline{\text { Positive }}$}

Then, for the two people who gave the highest amount, I will write down each person's name next to their donation, so everyone in your group knows what these two people gave. However, the donation made by the rest of the group who are not the two highest givers will be completely anonymous. I'll also announce the amounts out loud, and I will announce the names of the two highest givers out loud. Note that if any two amounts are exactly the same, one of the names will be randomly chosen to be listed first.

[REMAINING INSTRUCTIONS THE SAME FOR ALL TREATMENTS]

\section{At the End}

\section{You will take home the money in your blue "keep" envelope.}

We will send the money in the red "give" envelope to the Red Cross. Since the Red Cross can't accept cash, in a few days, we will take all the dollars out from the envelopes, and we will write a check in the total amount that the group chose to give and send it to the Red Cross. If you want to get a confirmation about the gift, please include your e-mail address in the sign out sheet and we will have the Red Cross automatically email you the total amount of gifts by this group.

\section{Quiz}

Sam gave the highest amount in the group. How will Sam's gift amount be announced and shown on the board?

$\square$ The gift amount only

$\square$ The gift amount plus Sam's name

$\square$ Sam's name only

Pat gave the lowest amount in the group. How will Pat's gift amount be announced and shown on the board?

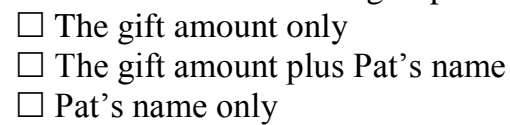

